\title{
Productivity, Competitiveness, and Territories of the Italian Medium-Sized Companies
}

\author{
Fulvio Coltorti ${ }^{1} \&$ Daniela Venanzi ${ }^{2}$ \\ ${ }^{1}$ M. Romani Department of Economic and Social History and Geographical Studies, Università Cattolica of \\ Milan, Milan, Italy \\ ${ }^{2}$ Department of Economics, Roma Tre University, Rome, Italy \\ Correspondence: Daniela Venanzi, Department of Economics, Roma Tre University, Rome, Via Silvio D’Amico \\ 77 - 00145 Rome, Italy. E-mail: daniela.venanzi@uniroma3.it
}

Received: September 29, 2017

Accepted: October 24, 2017

Online Published: November 5, 2017

doi:10.5539/ijef.v9n12p86

URL: https://doi.org/10.5539/ijef.v9n12p86

\begin{abstract}
The medium-sized firms (MEs) are the cutting-edge of the Italian manufacturing sector. They have a crucial role in influencing the behavior of the local systems whose they are part $(2 / 3$ of the total firms are located in industrial districts). This study investigates the drivers of Italian MEs' productivity, a fundamental aspect for assessing their ability to compete successfully. The classical approach (i.e. TFP) in measuring productivity is inapplicable to MEs, whose business model is characterized by: $i)$ specialized production at the leading technological edge; ii) organization based on vertical and horizontal supply chains, where the major players are small companies, specialized on single production phase; iii) marketing strategy focused on market niches, which are created/dominated thanks to product differentiation and continuous innovation and where MEs impose premium prices. The empirical evidence shows that: $i$ ) the RTS are not constant, but decreasing and size and productivity are inversely related; ii) the quality of the workforce is the major driver of productivity: companies that employ a low-salary workforce are less productive than those that use more skilled and costlier workers; iii) territories matter: knowledge-intensive service firms as well as infrastructures and managerial skills have a positive impact on productivity.
\end{abstract}

Keywords: drivers of productivity, TFP, industrial districts, impact of territories on productivity, Italian medium-sized firms

\section{Foreword}

The surveys conducted since the end of the nineties on Italian medium-sized enterprises (MEs from now on) have highlighted many positive characteristics of both their business model and their relationships with the territories where they are located (Note 1). Taking for granted the MEs' role, it is important to understand its strengths and evolution over time, together with the related impacts on the behavior of the local systems of which MEs are part. This study (Note 2) will investigate the drivers of Italian MEs' competitiveness, a fundamental aspect for assessing their ability to compete successfully and contribute to a better global competitiveness of the context in which they operate.

In Italy, the debate about the industrial policy is often biased by misunderstandings related to a lack of clarity in defining the firms' size, and to inaccurate calculations of productivity. In the first case, we can face some of the following problems:

- ambiguous classifications adopted by major European statistical institutions;

- aggregation in the same clusters of small individual firms, small firms that are part of local manufacturing networks, and medium-sized firms;

- lack of consideration of diverse ownership structures.

The classification of SMEs is mainly attributable to a European Commission recommendation of 2003, which suggested, as a criterion for identifying MEs, the range between 50 and 249 employees and sales below 50 million euros.

As a consequence, since in Italy there are few very large companies and many medium-sized firms, the 
performance of the class beyond 249 employees is included (and confused) among those of the largest firms (Note 3).

As far as productivity is concerned, the problems are related to methodological errors, e.g. the consideration of just the portion attributable to the "total factor productivity" (TFP from now on), and/or conclusions biased by a lack of statistical significance, due to data unreliability.

This paper is organized as follows:

a) first, the discussion of definitional issues related to productivity and competitiveness;

b) next, the description of relevant characteristics and dynamics of the MEs universe;

c) finally, the description and discussion of our empirical test (on the Italian manufacturing MEs universe), whose objective is twofold:

- to show some pitfalls of TFP approach to productivity measurement

- to identify the main drivers of MEs universe's productivity, when measured by using a more robust approach.

\section{The Theoretical and Empirical Framework}

\subsection{Productivity and Competitiveness: General Issues}

We define "competitiveness" as the firm's ability to stay on its market over the long term. This is essentially enabled by two achievements: consolidation or expansion of the market share, combined with the ability to earn positive margins. From an economic standpoint, we will measure competitiveness in terms of net operating margin, which represents the profit at factory level. On a unit basis, it is the margin generated by each employee, available for rewarding the providers of financial capital or set aside for strengthening equity or financing capital expenditures.

Productivity is measured in terms of "value": it is equal to the value added generated by each employee. This measurement avoids some flaws of alternative measures like measuring productivity based on volumes produced, or calculating the unit values in terms of hours worked. The pitfall of the first approach is attributable to globalization, since companies based in advanced countries incur higher costs compared to those in developing countries. Output must therefore be assessed in terms of "value", i.e. based on quality and performance of the manufactured goods, being obviously impossible to compete on low salaries. The weakness of the second approach, instead, is the lack of data on worked hours: this is attributable to both the individual firms and, even if we could collect some data, the unreliability of the available statistics. In fact, how should we account for the hours worked by white collars and, particularly, executives? How should we measure the top management's contribution, and how the hours worked outside the company could be quantified? (Manasse \& Stanca, 2006). Because of all these considerations, the employees' basis, although far from being perfect, seems to us the most effective parameter.

The relationship between productivity and competitiveness is based on labor costs and depreciation, since these expenses are subtracted from the former in calculating the latter. However, we also consider labor costs as a variable that conveys information on the "quality" of the employees involved in the manufacturing processes. Highly skilled people command higher than average wages, and the assessment of salary levels just represents the best way of identifying these differentials. Furthermore, studying the determinants of competitiveness assumes the availability of a sufficiently detailed and reliable database. Our source is the Mediobanca database, supported by the findings of the annual survey they conduct with Unioncamere. In the Appendix, we summarize the characteristics of this database that, in our view, is currently the best source for the type of investigation we want to conduct.

Turning to the concept of productivity, it is worth mentioning several "practices" most recently adopted by some scholars. These practices consist in the assumption that the appropriate measurement of productivity is the commonly called "total factor productivity" (TFP). For a better understanding, we should refer to the economists that first identified it, through the investigation of macroeconomic variables: Abramovitz (1956) and Solow (1957). For a long time, the "classics" stated that social progress is related to the productivity of labor (Note 4), but its main causes remain to be proved. The analyses of long-term data have highlighted the positive role, beyond the capital per employee, of the quality of human resources, the expansion of markets, and the reallocation of resources to the most productive industries, net of the reduction of working hours. However, most improvements in productivity (more than 65\% in 1964-1982, as shown by Denison's calculations, 1985, p. 113) are muddled into the concept of "residual" defined in 1955 by Abramovitz as "some sort of measurement of our 
ignorance about the causes of economic development" and called by Solow in 1957 "technical progress in a broad sense" (Solow, 1957 and 1987). Subsequently, this concept became popular as TFP.

The calculations of the total factor productivity ("residual") are often questionable, since they depend on arbitrary or theoretically debatable assumptions (Abramovitz, 1991, p. 17, where he quotes Denison). The micro data add further doubts about the effects and causes of the heterogeneity of individual companies and factories (Syverson, 2011). The most continuous macro surveys are those conducted on the United States, published by the local Bureau of Labor Statistics. According to the most recent data, in the period 1987-2012, the hourly productivity of labor in the private sector increased $2.1 \%$ per year, and the TFP's contribution was about $40 \%$ : hence, considering just the TFP implies an oversight of the most important portion of productivity. Moreover, this share is very volatile through time: over the last five years (2007-12) fell to $31 \%$. This degree of variability is not consistent with the "ideal" meaning attributed by scholars to the concept (that assumes slow and constant long-term developments) (Note 5). When we move from macro to micro data, other problems arise. On the one hand, there are the inaccuracies of the accounting systems: the listed companies adopt accounting principles that are different from those of family-owned firms, which are mostly very small. Furthermore, the latter often submit concise and opaque statements, due to tax evasion.

On the other hand, we cannot use deflators, at the firm's level, which could clean up data from the inflation effect. We use a very homogeneous database, in terms of both the type of firms (the universe of medium-sized companies) and the reliability of the financial statements (the medium size does not favor tax evasion and, at the same time, tax elusion through the creation of complex international networks of affiliates). We therefore conduct our tests disregarding firms that are either too small or too big. As already said, the indicator of productivity is the value added per employee. We will come back later to the TFP.

\subsection{The Italian Medium-Sized Companies: Business Model, Territories, Industries, Dynamics}

The last Mediobanca-Unioncamere survey (2013) counted 3,594 MEs. The most represented class belongs to the mechanical engineering sectors (39\% of companies), and about half of it is made by manufacturers of machinery and equipment. Personal and household goods are next (23\%) and, at the same level, food and chemicals (13\% each). Among the others, printing paper and metallurgy represent about $10 \%$ altogether. For our purposes, we took into consideration the universes identified in the last eight years (2003-2011) for a total of 31,512 observations. A significant characteristic of these companies over that period is that they mainly belong to district areas (66\%). The urban areas (four provinces with more than two million inhabitants) account for $13.5 \%$, and those that include large companies for $8.9 \%$. The two thirds of the district companies are based in populated areas (provinces with more than 500,000 people).

As far as the business model is concerned, MEs show the following characteristics: $i$ ) ownership mainly lies within a family; in fact, $70 \%$ of them are traditional family-owned firms; in another $20 \%$, family members are associated to third parties in management responsibilities; only the remaining $10 \%$ have various ownership structures (participations by mutual funds or other entities outside the control of the founder's family (Note 6)); ii) production is generally specialized on a single type of goods, and often on specific components; this allows continuous improvements that tend to place the companies on the leading technological edge. While product innovation is always an internal task, process innovation is mainly attributable to the use of state-of-the-art equipment or to the contributions of external consultants; iii) the operating organization relies on vertical and horizontal supply chains; the major players in these networks are mainly small companies, which are in charge of specific production phases. Last empirical findings show that each ME is connected to 36 suppliers, and the most important of these are based nearby: $62 \%$ of MEs are connected in "formal" networks, and $50 \%$ of the partners are based in the same province or region; $i v$ ) the marketing strategy is focused on market niches, which are created and controlled thanks to product differentiation and continuous innovation.

Hardly these characteristics allow companies to reach the size of the major international groups. In other words, the growth objective is pursued through a light and flexible organizational structure and the development, if needed, of networks and supply chains, as an alternative to the "internal" expansion. This option is confirmed by the high levels of permanence in the universe of the surveyed firms: an average of six years over the last eight years, taking account of the fact that the economic trends displace some companies above or below the formal thresholds (arbitrary by definition), at least temporarily in some cases. The companies always in the universe from 2003 to 2011 were 50\%, while $87 \%$ remained for more than four years. These rates of permanence do not significantly vary with locations, proving that the choice of not growing beyond a given level is a distinguishing feature of the Italian entrepreneurship.

Monopolistic competition is therefore the typical market structure among MEs: companies are usually able to 
impose premium prices vs. the producers of standardized goods. Most scholars claim that this situation can last in the short term: over longer time horizons, new entrants would reduce the profit margins to zero. This, however, does not happen when companies exhibit continuous and substantial innovation rates, which protect profits and represent a barrier to new entrants. In any case, we should expect that the returns to scale (RTS from now on) for MEs will decrease with the increase in size. This phenomenon was already described by Piero Sraffa (1926), who referred to the "particular markets" mentioned by Marshall (Principles, Book IV, Ch. XI, 5).

MEs' location affects their industry profile. In the urban areas (UAs from now on), that represents $13.5 \%$ of the observations, mechanics, metallurgy, and chemicals prevail; these companies produce $69 \%$ of the total value added. This share decreases to 63\% in the highly populated district areas (DI_P from now on; $43 \%$ of the observations) and to 55\% in the low-populated ones (DI from now on). Personal and household goods are particularly important in the district areas: $24 \%$ in the non-populated areas and 29\% in the highly populated ones. In the remaining territories, beyond the prevalence of the metal and mechanical industry, food is also important (between 22 and 24\%).

In absolute terms, productivity is higher in the more populated areas (urban, districts, and large firms areas). The value added per employee (VAxEMP), at current values, exceeded the pre-crisis levels in 2011, but the overall performance of the urban areas was even better. If we consider the productivity ratios net of the industry impact (industry-relative net operating margin per employee) (Note 7), we see a slight advantage of firms in UAs, while the district areas maintain a very narrow margin in the highly populated provinces, and relative disadvantages in the remaining areas (Figure 1).

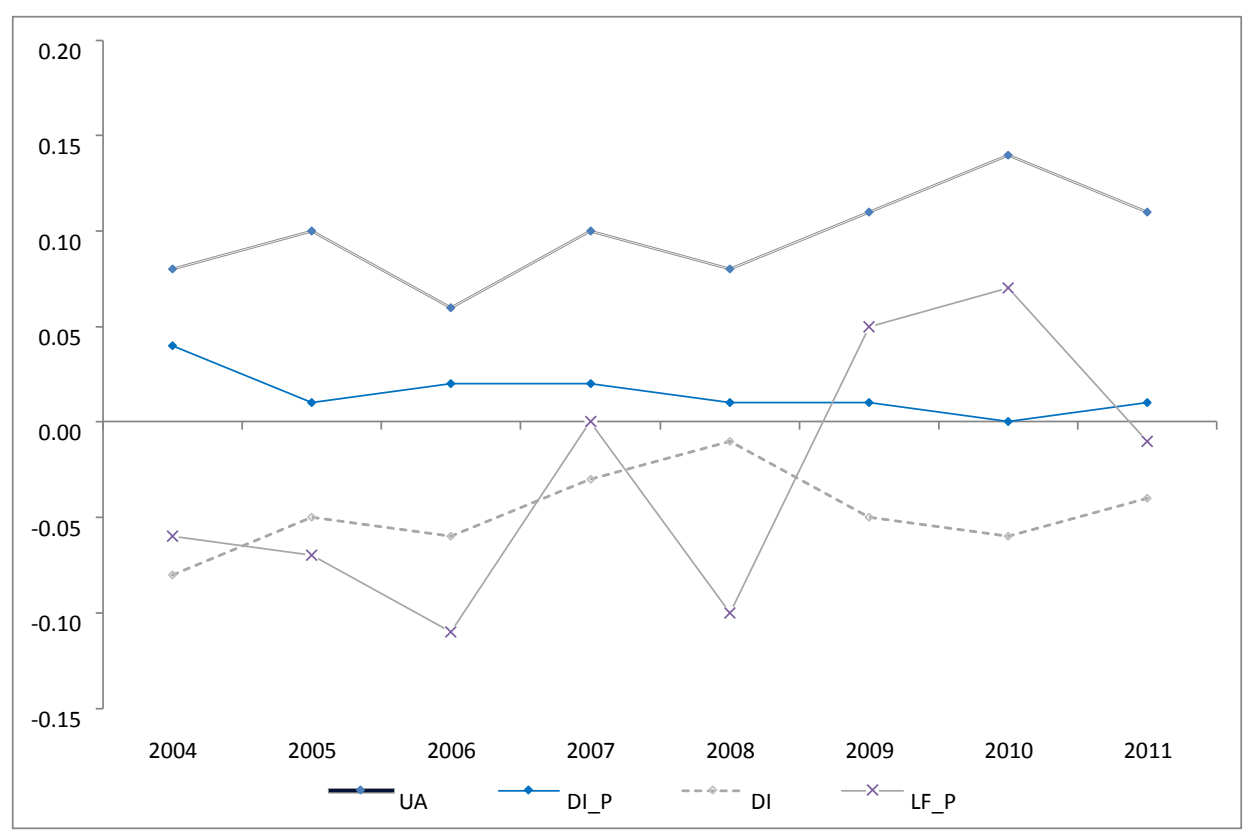

Figure 1. Net operating margin per employee (industry-relative measure)

(firm-year observations - period 2004-2011)

The apparent superiority of the UAs (Table 1) is largely attributable to the prevalence of smaller MEs (that, as we will also see below, are the most productive) and, within this context, to the higher productivity of food, personal and household goods industries. Presumably, in these areas the supply chain relationships maintained by firms with the district areas are particularly relevant, and this is confirmed by their lower endowment of capital invested in operations. On the other hand, their direct export capabilities do not represent an advantage: in the UAs, the per-firm export sales are $16 \%$ lower than the overall average and $26 \%$ lower than the average in the DI_P areas. The gap from the latter grows to 33 points in the personal and household goods and remains around 16 points in metal and mechanical engineering industries. The UAs' advantage is therefore twofold: smaller and, therefore, more flexible firms, that exploit their relationships with the districts and a lower dependence from foreign markets that, as we will see, have a negative impact on productivity. 


\subsection{The TFP's Shortcomings}

As we said before, the international literature favors TFP as a measure of productivity, in the analyses of both the aggregate data and the local differentials, starting from the data on the individual firms, in cross-sectional and longitudinal comparisons (Syverson, 2011). The TFP is obtained as a residual of the Cobb-Douglas production function or from subsequent variations that make the function more complex, through the inclusion of further differentiations of the production factors; it measures the residual of the linear regression (using logarithmic transformation of the variables) of output (i.e.e sales or value added) as dependent variable on production inputs (i.e. labor and industrial capital) as explanatory variables.

The shortcomings of the Cobb-Douglas production function, together with the related TFP measure, are numerous (Note 8): we briefly summarize them below.

Table 1. Value added per employee (\% of industry average - period: 2004-2011)

\begin{tabular}{lcccccc}
\hline \multicolumn{1}{c}{ Area/Industry } & $\begin{array}{c}\text { Metal and mechanical } \\
\text { engineering }\end{array}$ & Chemicals & $\begin{array}{c}\text { Paper and } \\
\text { printing }\end{array}$ & $\begin{array}{c}\text { Personal and } \\
\text { household goods }\end{array}$ & Food & Total $(*)$ \\
\hline Urban areas (UA) & 108.0 & 108.1 & 108.3 & 125.8 & 110.0 & 112.8 \\
$\begin{array}{l}\text { District areas: } \\
\quad \text { Highly populated (DI_P) }\end{array}$ & 101.2 & 96.4 & 104.4 & 99.4 & 106.9 & 100.2 \\
$\quad$ Others (DI) & 93.5 & 100.3 & 95.8 & 93.6 & 93.0 & 92.8 \\
Large firms areas (LF) & 103.2 & 85.6 & 102.5 & 107.0 & 109.0 & 103.3 \\
$\quad$ Highly populated (LF_P) & 95.8 & 97.9 & 73.5 & 88.4 & 94.7 & 96.1 \\
$\quad$ Others (LF) & 96.2 & 103.3 & 86.6 & 102.6 & 90.2 & 97.7 \\
Residual areas (RES) & & & & & & \\
\hline
\end{tabular}

1) The assumptions behind the production function are rather unrealistic:

- First of all, the assumed existence of an aggregate production function, at the level of either the overall economy or the individual industries, of which the production functions of the individual industries (in the first case) or the subsequent breakdowns by product-market segment, locations, size class, etc. (in the second) would be scaled-down identical copies;

- Second, the assumption that technical progress does not imply product innovations (i.e. it does not modify the quality of production) and is not incorporated in capital goods, but happens like a "blessing from heaven" and uniformly moves upward the production function (neutral technical progress); evidently, this implies that the drivers of productivity (among which: territories, size, etc.) only shift the production function without affecting, crosswise, all the input factors and their mix: in other words, the drivers of productivity only affect the regression intercept, and not the production function coefficients (i.e. the marginal productivity of capital and labor) and its shape;

- Third, the existence of perfect competition, and a distribution theory based on the marginal productivity of factors: i.e. the unit remuneration of factors - respectively, unit salary and interest rate - equal the corresponding marginal productivities;

- Finally, the assumptions that technology is characterized by constant RTS, changes in the use of inputs would not imply adjustment costs, so that companies are always in a long-term equilibrium, while the economy is characterized by full employment and total saturation of the production capacity.

These assumptions, if related to the Italian MEs, are not acceptable: these firms are focused on market niches in which they are price-setters instead of price-takers, and face decreasing RTS; product innovation is a value-creation strategy, the production mix varies among firms and over time, and the production factors' unit costs do not equal their marginal productivity.

2) The TFP is not an observed or observable quantity, but the result of the interpretation of a residual produced by the interaction of observable entities, in turn interpreted according to non-observable and unrealistic assumptions;

3) The TFP only catches a portion of productivity, since it just considers the so-called disembodied technical change (residual vs. labor and industrial capital inputs) and not also the embodied technical change, which implies different quality levels and, hence, different prices of the input factors (Mahadevan, 2003). The TFP is normally estimated on deflated values of products and consumption of goods and services, using sector-specific deflators, and ignoring differences among sectors in the average quality of products: for 
example, when product differentiation characterizes some sectors in comparison to others.

\section{The Empirical Test on the Italian MEs' Universe: Design and Results}

\subsection{Empirical Evidence on TFP}

We estimated a production function $\grave{a}$ la Cobb-Douglas on our universe of Italian MEs, with the purpose of emphasizing the following items:

a) the RTS are not constant, but decreasing;

b) in the production function, the territories affect the coefficients of labor and industrial capital: it is therefore reductive to consider the drivers' (in this case, territories') impact just on the residual (the TFP);

c) when the estimate of the production function is based on the total values (value added, employees, invested capital, etc.) instead of on the unit values (value added and invested capital per employee), the resulting residual is biased in favor of the larger size. This depends on the fact that, if the observed production function formally differs from the expected one, and the relationship with the inputs is not (or not totally) log-linear, we find in the residual (tout court assumed as TFP) a component that is still correlated with the production scale: this, when we estimate the TFP's drivers, could trigger a sequence of distortions. The findings of some recent studies (Accetturo, Di Giacinto, Micucci, \& Pagnini, 2013; Cainelli, Montresor, \& Vittucci Marzetti, 2013; Di Giacinto, Gomellini, Micucci, \& Pagnini, 2012) show a productivity advantage for the largest firms and the urban areas vs. the districts. This, indeed, could depend on the positive (and spurious, as we explained above) correlation between TFP and size, since the two territories show a non-homogeneous distribution of firms in terms of size: the large ones in the urban areas, and the small ones in the districts. Evidently, the problem would be solved using, in estimating TFP, the Cobb-Douglas function on values per employee, but in this case the restriction on constant RTS would be assumed (see below).

Starting from the following relationship

$$
Q_{i(\in S) t}=\Phi_{i t} L(\text { bcollar })_{i t}^{\alpha_{b c s}} L(\text { wcollar })_{i t}^{\alpha_{w c S}} K_{i t}^{\beta_{S}}
$$

and obtaining the transformed logarithmic (lowercases identify the logarithms of the original variables)

$$
q_{i(\in S) t}=\alpha_{b c S} l(\text { bcollar })_{i t}+\alpha_{w c S} l(\text { wcollar })_{i t}+\beta_{S} k_{i t}+\phi_{i t}
$$

the productivity, in terms of TFP (logarithm of $\Phi_{i t}=\phi_{i t}$ ), is just related to the residual (assuming consistent estimates of $\alpha_{b c s}, \alpha_{w c S}$ e $\beta_{S}$, at the industry level).

$$
\hat{\phi}_{i t}=q_{i t}-\hat{\alpha}_{b c S} l(\text { bcollar })_{i t}-\hat{\alpha}_{w c S} l(\text { wcollar })_{i t}-\hat{\beta}_{S} k_{i t}
$$

We estimated (2) by regressing the logarithm of value added (deflated using the average implicit deflator of the manufactured goods, taken from the Eurostat data for Germany and France (Note 9)) on the number of employees (distinguishing between blue and white collars) and the book values of fixed and working capital: the latter represents, among MEs, a relevant share of the invested capital (60\% on average over the entire period, and $55 \%$ in the last three years). We first estimated the inputs' coefficients by industry, and subsequently, in order to support the statement under b), by industry and territory, using the classification of territories proposed by Becattini and Coltorti (2006) and including in the function both the industry fixed effects and the year-region interaction effects (Note 10).

In estimating the function, we ignored the problem of the potential endogeneity produced by the simultaneity of inputs and output (in the literature, the problem is solved using the approach proposed by Levinsohn and Petrin, 2003), since the empirical evidence of previous studies shows minimal effects if compared to estimates based on fixed-effects models. Instead, we did not ignore the problem of the serial autocorrelation of residuals, appropriately controlling it with a first-order auto-regressive (heterogeneous) model: the linear correlation of both the value-added residuals and the value-added per employee in periods $t$ and $t-1$ is very high (around 75-80\%), decreases with the lag, but remains high even after several years: this because the firms' relative position in terms of productivity is rather stable over time. This finding is confirmed by previous studies (Abraham \& White, 2006).

The regression results are shown in Table 2:

- part A shows the coefficients of the production function, estimated at the industry level;

- part B shows the statistically significant differentials (significance of at least 90\%) found in the territories (a logarithm value of 0.05 roughly corresponds to $+5 \%$ ).

We can see that the urban areas differ in terms of higher marginal productivity of white collars and invested 
capital, and lower marginal productivity of blue collars, while in the textile, apparel, leather, and mechanical industries, districts have a higher marginal productivity of blue collars. Furthermore, in our case, the average values of the coefficients are strongly affected by MEs based in district areas (both highly and low populated), that represent about two thirds of the universe. The RTS are decreasing in all industries: the Student's $t$ test (data omitted for brevity), performed on the coefficients measured at the industry level, rejects, at a $99.9 \%$ level of significance, the hypothesis of constant returns for all industries, except for the chemical-pharmaceutical one.

In order to prove point c) above, we performed again the estimate, using in this case the formulation (4) of the production function, in which data are expressed in per-capita figures (always operating on logarithmically transformed variables (Note 11)), including in the regression, for the sake of homogeneity, both the fixed industry effects and the year-region interaction effects, but ignoring for simplicity the location effects.

$$
\left(\frac{Q}{L}\right)_{i(\in S) t}=\Phi^{\prime}{ }_{i t}\left(\frac{K}{L}\right)_{i t}^{\beta_{S}}
$$

Comparing the residuals of the two regressions, we see a positive correlation (significant at the 99\% level) of the residual calculated on total values with the number of employees, while the residual calculated on unit values is negative. Both residuals, furthermore, are positively correlated with the gross operating margin.

Table 2. Estimate of Cobb-Douglas production function (total values)

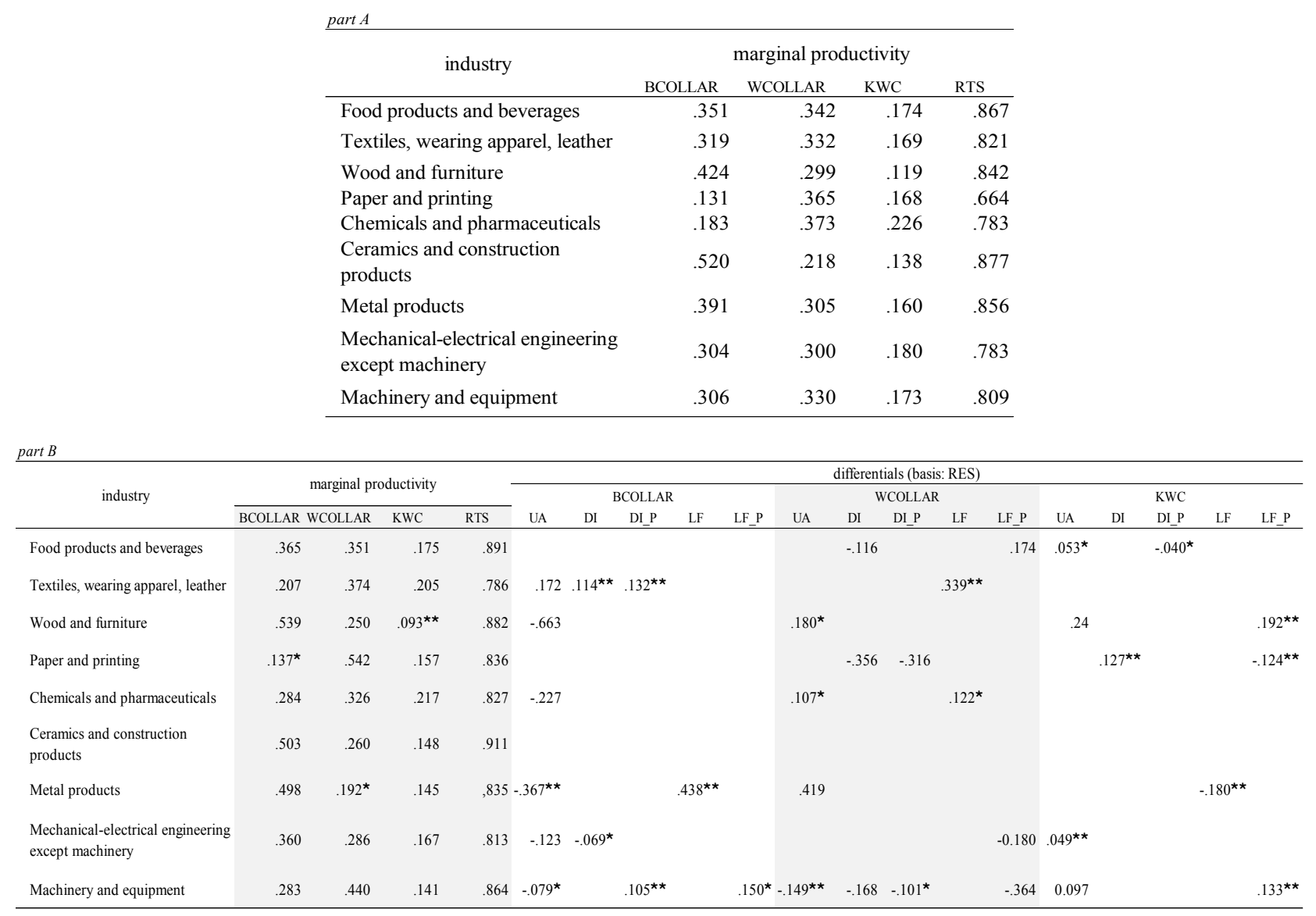

no symbol: sign $\geq 99 \% ; * *: 99 \% \geq \operatorname{sign} \geq 95 \% ; *: 95 \% \geq \operatorname{sign} \geq 90 \%$

\subsection{The Drivers of the Italian MEs' Productivity}

The international literature has extensively investigated the drivers of productivity: see, among all, the complete review in Syverson (2011). Based on this broad literature, we identified the drivers listed in Table 3, distinguishing them depending on whether they are under or outside the firm's control, even if this distinction could seem somewhat artificial for some drivers, due to the interactions and frequent overlaps between the two 
categories. Each continuous variable (covariate) was expressed both as an industry average (avg suffix) and as an industry-relative value (stu suffix), measured as a difference between the value of the variable for the individual firm-year observation, and the average industry value for the same year, divided by the industry volatility (standard deviation) in the year: the adjustment with the standard deviation is explained with the fact that the differences from the average industry value are the more relevant and significant the lower is the variability among firms in the industry.

This decomposition of each covariate aims at separating the impact on productivity attributable to the nature of the firm's business-industry from the firm-specific component, i.e. from the relative position of the individual firm vs. those of the same industry.

Table 3. Productivity drivers

\begin{tabular}{|c|c|c|}
\hline driver & proxy & acronym \\
\hline \multicolumn{3}{|l|}{ under firm's control } \\
\hline $\begin{array}{c}\text { invested capital per } \\
\text { employee }\end{array}$ & $\begin{array}{l}\text { - net tangible assets }+ \text { inventories }+ \text { trade receivables }- \text { trade payables per } \\
\text { employee (deflated book values) }\end{array}$ & - KWCxEMP_def1 \\
\hline quality of labor & $\begin{array}{l}\text { - labor costs per employee (deflated) } \\
\text { - blue collars on total employees }\end{array}$ & $\begin{array}{l}\text { - } \quad \text { CLABxEMP_def } \\
\text { - } \quad \text { pc_OPE }\end{array}$ \\
\hline quality of industrial & - capital expenditures per employee (deflated) & - INVxEMP_def1 \\
\hline capital & $\begin{array}{l}\text { - depreciation degree of tangible assets (accumulated depreciation on } \\
\text { tangible assets) }\end{array}$ & - $\quad$ DEPD \\
\hline quality/innovation of & - trade-off between prices and cost of good sold & - $\mathrm{ROS}$ \\
\hline product & - growth rate of sales & - $\quad$ GROWTH \\
\hline experience/learning by & - age of the firm & - $\mathrm{AGE}$ \\
\hline doing & $\begin{array}{ll}\text { - } & \text { size } \\
\text { - } & \text { international experience (export on sales) }\end{array}$ & $\begin{array}{ll}\text { - } & \text { SIZE }[1,2,3] \\
\text { - } & \text { pc_EXP }\end{array}$ \\
\hline managerial skills & - outperformance vs competitors & - ROI_stu \\
\hline structure of operations & $\begin{array}{l}\text { - labor costs on sales } \\
\text { - costs of external supplies and services on sales } \\
\text { - } \quad \text { fixed costs on total costs }\end{array}$ & $\begin{array}{ll}\text { - } & \text { pc_CLAB } \\
\text { - } & \text { pc_CSERV } \\
\text { - } & \text { pc_CFIX }\end{array}$ \\
\hline financial constraints & $\begin{array}{l}\text { - } \quad \text { financial leverage } \\
\text { - incidence of liquid assets on total assets }\end{array}$ & $\begin{array}{ll}- & \text { LEV } \\
- & \text { LIQ }\end{array}$ \\
\hline \multicolumn{3}{|l|}{ outside firm's control } \\
\hline external competition & - importation of finished goods on production value (at industry-year level) & - $\quad$ int_IMPORT \\
\hline export intensity & - exportation of finished goods on production value (at industry-year level) & - int_EXPORT \\
\hline infrastructure/PA & $\begin{array}{ll}\text { - } & \text { NORTH-EAST regions + Tuscany, Marche, Umbria } \\
\text { - } & \text { NORTH-WEST regions (Piedmont, Aosta Valley, Liguria and Lombardy) } \\
\text { - } & \text { SOUTH regions + Lazio }\end{array}$ & $\begin{array}{l}\text { - } \quad \text { GEO }[\mathrm{NEC}, \mathrm{NW} \text { and } \\
\text { SOUTH] }\end{array}$ \\
\hline $\begin{array}{l}\text { local system of operations } \\
\quad \text { organization }\end{array}$ & 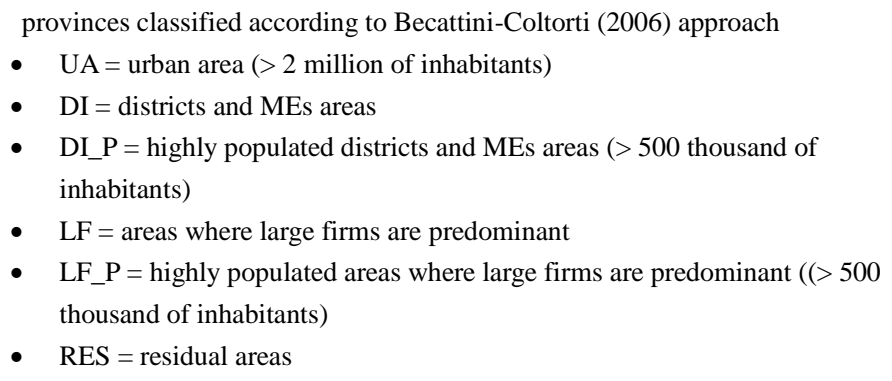 & $\begin{array}{l}\text { - } \\
\text { TERRIT [UA, DI, } \\
\text { DI_P, LF, LF_P and } \\
\text { RES] } \\
\text { - TERRIT_ROUGH } \\
\text { [simple breakdown: } \\
\text { UA, DI, DI_P, } \\
\text { OTHER] }\end{array}$ \\
\hline manufacturing and & - manufacturing density & - DENS_MANU \\
\hline services density & $\begin{array}{l}\text { - density of external services to firms } \\
\text { (KIS=knowledge intensive services: } \text { LKIS=low KIS) }\end{array}$ & - $\quad$ KIS_total \\
\hline
\end{tabular}

We therefore regressed on the universe of MEs, in the period 2004-2011, the measure of productivity in terms of value added per employee, on the above-mentioned drivers, with the following specifications:

- we controlled the serial autocorrelation of the dependent variable, specifying an auto-regressive and heterogeneous model of the first order (using, for this purpose, the SPSS mixed models (Note 12) and estimating the coefficients with the maximum likelihood method); 
- we ignored both the lagged drivers and the growth rates, which can only be applied to the firms' closed sample, since we wanted to estimate a general model, applicable to the MEs' universe, and not to sub-sets;

- in order to control the economic trends, we included the fixed time effects, omitting the industry fixed effects, since the industry effect is better caught by the avg component of the determinants specified in the model, which anyhow varies over time;

- we used locations and size classes, both as level factors (i.e. intercept) and as interaction effects with the covariates (slope of their relationships with the dependent variable), for which it is reasonable to assume that the impact on productivity varies along with territories and size. Our focus on territories, defined according to the classification by areas (Becattini-Coltorti, 2006), aims at verifying the impact on productivity of the economies of aggregation; the highly populated areas would offer a number of benefits, such as pooling of the labor market, proximity to local suppliers and target markets, spillover of technologies and knowledge; on the other hand, they would suffer some relevant drawbacks, such as congestion costs, higher costs of spaces, etc. The highly populated areas would also trigger selection economies (Combes, Duranton, Gobillon, Puga, \& Roux, 2012): both as an ex post process, since larger markets would attract more entrants, favoring more competition and the abandonment of less efficient and competitive firms, and as an ex ante sorting process, since less efficient firms and less skilled workers would avoid the more dense and competitive areas. Apart from the well-known advantages of the district areas in terms of economies of aggregation and cooperation within the district communities, specialization and related externalities (Becattini, 2000 and 2007), the weak points would be attributable to the negative effects of an overcrowding of firms and workers in relatively small areas. Our focus on size, instead, aims at verifying the relative impact on productivity of the economies of differentiation vs. the economies of scale; in the MEs' case, we expect a higher productivity of the smaller ones, since they are mainly focused on product-market niches, and base their competitive advantage not so much on cost reductions thanks to better efficiency, but on the quality of products and related services, that allows premium prices (Coltorti \& Garofoli, 2011).

The general specification of the model is summarized by the following relationship (5), while Table 4 shows the model's results with the best fit (i.e. including only the statistically significant variables).

$$
\begin{gathered}
\qquad A \times E M P_{i t(\text { industry,territory,size })}= \\
f\left(y e a r \text { fixed effect, territory dummy, size dummy, drivers } s_{i t}, \text { territory dummy } \times\right. \\
\text { drivers } \left._{i t}, \text { size dummy } \times \text { drivers }_{i t}\right)
\end{gathered}
$$

Here are our main findings:

a) the time dummies (omitted for brevity) identify the cyclical effects in the period taken into consideration;

b) the territories do not influence productivity as fixed effects, but mediate other determinants, amplifying or mitigating their impact on productivity;

c) we found an inverse relationship between size and productivity, and this is consistent with the MEs' business model, characterized by production specialization and creation of market niches, in which premium prices can be exploited; the increase in production could undermine the MEs' monopolistic position insured by a dominant role in a narrow niche. Beyond the fixed effect, the smaller size amplifies the productivity of more skilled workers (CLABXEMP_stu) and better products (ROS_stu), compared to the industry average;

d) a relevant driver of MEs' productivity is the quality of the workforce [other studies found the same effect: Dosi, Grazzi and Moschella (2013), at firm level; Maza, Villaverde and Hierro (2009), at regional level], combined with capital per employee (KWCxEMP): in terms of industry average (CLAB_avg), each additional euro of cost of labor per employee implies a value added increase of more than 1.4 euro. Each unit of (standardized) differential vs. the industry average (CLAB_stu), generates about 12 additional euros of value added; this emphasizes the positive impact of activities that demand more qualified skills, under the influence of territories, defined in terms of organization of production (we used the TERRIT_ROUGH classification): the localization in the UAs improves the productivity of labor in companies that use more skilled workforce, while the localization in districts has a negative effect; the incidence of blue collars reduces productivity, but this does not apply to companies in the district areas, where even blue-collar workers are highly specialized and skilled;

e) the ratio 'cost of labor/revenue', differential vs. the industry average (pc_CLAB_stu), reduces productivity; this does not contradict, but further qualifies the above conclusion: if workers are more productive, the higher 
cost of labor goes together with higher value added and revenue (products of better quality requested by the market), and therefore the different proportion of these variations is relevant;

f) equally important, as a driver of productivity, is product quality, in terms of both industry characteristic and firm's differential vs. the industry average: the latter seems amplified among firms based in highly populated districts and urban areas (the former effect, however, is about twice as much the latter);

Table 4 . The results of the explanatory model of productivity

\begin{tabular}{|c|c|c|c|}
\hline drivers & estimate (a) & drivers & estimate (a) \\
\hline intercept & -9.31 & {$[\mathrm{SIZE}=1] *$ ROS_stu } & 11.62 \\
\hline$[\mathrm{SIZE}=1]$ & 9.52 & [SIZE $=2] *$ ROS_stu & 4.86 \\
\hline$[\mathrm{SIZE}=2]$ & $2.89^{\star \star}$ & {$[\mathrm{SIZE}=3] *$ ROS_stu } & $0^{\mathrm{b}}$ \\
\hline$[\mathrm{SIZE}=3]$ & $0^{\mathrm{b}}$ & [NEC] * INVxEMP_stu & 0.33 \\
\hline CLABxEMP_avg_def & 1.43 & {$[\mathrm{NW}] *$ INVxEMP_stu } & 0.48 \\
\hline CLABxEMP_stu & 11.68 & [SOUTH] * INVxEMP_stu & $0.08^{\circ}$ \\
\hline KWCxEMP_avg_def1 & 0.07 & [UA] $*$ CLABxEMP_stu & 1.49 \\
\hline KWCxEMP_stu & 5.55 & [DI] * CLABxEMP_stu & $-0.91^{\star \star}$ \\
\hline CLABxEMP_stu * KWCxEMP_stu & $0.20^{\star \star}$ & [DI_P] $*$ CLABxEMP_stu & $-0.06^{\circ}$ \\
\hline pc_CLAB_stu & -7.78 & [OTHER] * CLABxEMP_stu & $0^{\mathrm{b}}$ \\
\hline pc_CSERV & -0.13 & [UA]* KWCxEMP_stu & $-1.07^{\star \star}$ \\
\hline pc_OPE_stu & -1.26 & [DI] * KWCxEMP_stu & $-1.09^{\star \star}$ \\
\hline pc_CFIX & 0.50 & [DI_P] * KWCxEMP_stu & $0.43^{\circ}$ \\
\hline ROS_avg & 2.34 & [OTHER] * KWCxEMP_stu & $0^{\mathrm{b}}$ \\
\hline ROS_stu & 9.61 & {$[\mathrm{AU}] *$ pc_OPE_stu } & $0.57^{\circ}$ \\
\hline DEPD_stu & 0.72 & {$[\mathrm{DI}] *$ pc_OPE_stu } & $1.03^{\star}$ \\
\hline AGE & -0.06 & [DI_P] * pc_OPE_stu & $1.25^{\star \star}$ \\
\hline LIQ_stu & 1.69 & [OTHER] * pc_OPE_stu & $0^{\mathrm{b}}$ \\
\hline ROI_stu & 0.8 & {$[\mathrm{UA}] *$ pc_CLAB_stu } & $-1.36^{\star \star}$ \\
\hline DENS_MANU & -0.19 & {$[\mathrm{DI}] *$ pc_CLAB_stu } & $0.06^{\circ}$ \\
\hline KIS_somma & $0.18^{\star \star}$ & [DI_P] *pc_CLAB_stu & $-0.88^{*}$ \\
\hline LKIS_somma & -0.29 & [OTHER]*pc_CLAB_stu & $0^{\mathrm{b}}$ \\
\hline int_EXPORT & -0.14 & {$[\mathrm{UA}] *$ ROS_stu } & $0.79^{\star \star}$ \\
\hline$[\mathrm{SIZE}=1] *$ CLABxEMP_stu & 1.53 & {$[\mathrm{DI}] *$ ROS_stu } & $0.04^{\circ}$ \\
\hline$[\mathrm{SIZE}=2] *$ CLABxEMP_stu & $0.49^{\circ}$ & [DI_P] * ROS_stu & 1.42 \\
\hline$[\mathrm{SIZE}=3] *$ CLABxEMP_stu & $0^{\mathrm{b}}$ & [OTHER]* ROS_stu & $0^{\mathrm{b}}$ \\
\hline$[\mathrm{SIZE}=1] *$ pc_CFIX & -0.46 & a: dependent variable = VAxEMP_def & \\
\hline$[\mathrm{SIZE}=2] *$ pc_CFIX & -0.12 & \multirow{2}{*}{$\mathrm{b}$ : this parameter is set $=0$ since redundant } & \\
\hline$[\mathrm{SIZE}=3] * \mathrm{pc} \_$CFIX & $0^{\mathrm{b}}$ & & \\
\hline \multicolumn{4}{|c|}{ no symbol: sign $\geq 99 \% ;{ }^{\star \star *}: 99 \% \geq \operatorname{sign} \geq 95 \% ;{ }^{\star}: 95 \% \geq \operatorname{sign} \geq 90 \% ;{ }^{\circ}: \operatorname{sign} \leq 90 \%$} \\
\hline $\begin{array}{l}\text { Akaike information criterion (AIC): } 254 \\
\text { adjusted R2 (ANCOVA): } 0.683\end{array}$ & Schwarz bayesian & information criterion (BIC): 254880.834. & \\
\hline
\end{tabular}

g) the invested capital per employee, adjusted for inflation (KWCxEMP_avg_def1) gets an average return of 7\% in terms of productivity, and an increase of 5.5 euros for each unit of standardized differential vs. the industry average; the impact of the latter is about $20 \%$ lower among firms based in UAs and DIs, compared to other territories. The accounting record of fixed capital is not necessarily accurate in measuring the service flows produced by the stock of capital. However, when we use the perpetual inventory method (adjusted value of stock at the beginning of period + capital expenditures - assets disposals + other acquisitions - other divestments) in measuring both the fixed capital and the related accumulated depreciation (obviously, only for the sample that includes the same firms over the entire period of interest), we obtain figures that are strongly correlated to the book values (i.e. correlation of $99 \%$ if we consider both the fixed and working capital, $97 \%$ when only the former is included). Therefore, the effects of this alternative measurement on the explanatory model are not important, although the coefficients would change (different fixed capital values); 
h) where the investment policies are more intense than the industry average, the North-West and North-East infrastructural primacy vs. the Southern regions seems to be relevant in terms of investment productivity;

i) the degree of vertical integration has a favorable impact on productivity (the coefficients of pc_CFIX and pc_CSERV are, respectively, positive and negative), but this effect is practically irrelevant for smaller MEs and decreases for those of the middle class;

j) the managerial skills have a positive impact on productivity as well (ROI_stu);

k) the manufacturing density and that of low knowledge-intensive services (trade, transportation, rentals, leasing, postal, etc.) reduce productivity, while that of high knowledge-intensive services (high-tech, finance, management, consulting, etc.) increases it. This evidence indirectly parallels the Becattini-Coltorti's classification of territories (Note 13), since these different densities significantly differ among them: in particular, the districts present a higher manufacturing density, respectively of 18.5 employees per 100 workers (DI_P) and 16 (DI), compared to average values of 10-11 for the other territories. Analogously, the UAs differ in terms of knowledge-intensive services: their density is more than twice the average of the other areas (respectively, 18 vs. values between 8 and 9); the density of the more traditional services is higher as well in the UAs (about 26 on average), but in this case the differences are less important: about 21 on average for highly populated large firms areas and residual provinces, about 19 on average for the districts;

1) the international experience of individual firms doesn't seem to affect their productivity (the ratio export/revenues - pc_EXP - is not statistically significant): this apparently counterintuitive data (recent studies found a significant inverse causal link: Dosi et al., 2013) can be explained with the consideration that the ratio export/revenues for an individual firm is not an appropriate indicator of its international competitiveness, since many MEs sell their products to larger firms that, in turn, export very large amounts of production (for example, the Albini fabrics sold to Armani or other large firms). However, the propensity to export, if measured as industry characteristics (int_EXPORT), shows a negative effect on productivity: we could explain this evidence in terms of higher competitiveness in more internationally oriented sectors, and/or more expensive distribution systems and logistics in the foreign markets;

m) a higher relative degree of amortization of fixed assets vs. the industry average positively affects productivity, while we could have expected an inverse relationship, if interpreted as a proxy of the quality of capital: the positive relationship could be explained in terms of better production efficiency in case of high saturation of the production capacity (of which the degree of amortization could be a proxy);

n) younger MEs are more productive, probably because they face a stronger competition during their development and consolidation process; on the other hand, in case of family businesses, an older age and generational changes could imply problems of governance; previous studies (Bloom \& Van Reneen, 2007) found that, in family businesses, the founder's heirs are less managerially skilled;

o) firms with larger liquid assets have an advantage in terms of productivity, presumably because they do not suffer financial constraints on their investments; however, in our study, the financial leverage doesn't seem to be a statistically significant factor.

The model explains more than $2 / 3$ of the variability of the dependent variable: the adjusted $\mathrm{R}^{2}$ is $68.3 \%$. Presumably, this is an over-estimate of the model's explanatory power, since for some of our determinants there is a problem of endogeneity, i.e. the causal relationship between driver and productivity could actually be inverse: for example, with variables such as ROS, ROI, unit cost of labor, capital per employee, export orientation, etc.

This problem is only apparently emphasized by the simultaneity, in the model, between determinants and dependent variable, since we found an important serial auto-correlation of productivity (the correlation of residuals is 0.84 , and the Wald's test is significant at $99.9 \%$ ). Hence, the problem would not be solved, but only mitigated, using a lag of one or more years in measuring the determinants, with the result, however, of analysing in this case subsets of MEs instead of the entire population.

The Granger's causality test, performed on the independent variables potentially affected by endogeneity, does not exclude inverse causality, but the causal link in the direction specified in the model is strongest.

On the other hand, the problem of endogeneity biases all studies on productivity. A frequently adopted solution is that of using variables that are calculated on elementary data collected via surveys, disregarding financial statements: therefore, instrumental and causative variables, instead of effects. For example, managers' quality, measured in terms of adopted best practices (Bloom \& Van Reenen, 2007), quality of work in terms of education, training, previous experiences in the same industry or firm (see also Syverson, 2011), etc. 
This type of analyses, however, suffer a number of limitations, such as the subjectivity and low reliability of the collected data, and the possibility of collecting them only for small samples of companies.

\section{Conclusions}

In this paper, we identified and described the major determinants of productivity, one of the most relevant drivers of Italian MEs' competitiveness, thanks to the use of an exhaustive and homogeneous database, built on high-quality company data.

Reminding that we are exclusively referring to manufacturing firms, we can summarize our main conclusions as follows.

Firstly, as far as territories are concerned, evidence shows that MEs typically characterize the "district" areas: $2 / 3$ of the total firms are located in districts, attracted by a social context with a high concentration of entrepreneurial skills and a propensity to create networks and supply chains. The large urban areas (Milan in particular) produce positive effects, but they are limited only to a small number of MEs (13.5\%), and are characterized by a smaller firms' size and heterogeneity; the best results also depend on good relationships between these firms and the districts. Moreover, knowledge-intensive service firms have a positive impact on productivity, but their contribution is not limited to the territories in which they operate, thanks to the opportunities created by more widespread mobility, improved transports and communications. On the contrary, a high manufacturing density negatively affects productivity, probably due to congestion problems; in fact, the aggregation externalities are implicit "in re ipsa", if we consider that $2 / 3$ of MEs are in district areas. Infrastructures and managerial skills have a positive impact. The former ones tend to differentiate results at the expense of Southern Italy MEs.

Secondly, the quality of the workforce, measured in terms of per-capita salary level, is the major driver of productivity. We must therefore reverse the generally accepted causal relationship: companies that employ a low-salary workforce are less productive than those that use costlier per-capita workers, when combined with higher per-capita investment and higher quality of productions. The resulting "political" implication recommends higher-skill productions.

Thirdly, there is an inverse relationship between size and productivity, and this is confirmed by MEs' business model: manufacturing specialization and marketing policies aimed at creating market niches that could be dominated thanks to better competencies and innovation, resulting in the ability to command premium prices. On the contrary, increasing size and related diversification tend to reduce firms' monopolistic power in larger markets. The econometric analysis confirmed decreasing RTS.

Finally, the relationship between propensity to internationalize and productivity is not significant, also because MEs often sell their productions to large Italian exporters; a strong liquidity tends to produce positive results, as an antidote to credit crunch.

Our analysis presents some limitations. It is applicable only to geographical areas (like Italian industrial districts) characterized by widespread entrepreneurial skills and settled tacit knowledge, transmittable over time and, preferably, in personal and household goods industries. In fact, these features favor local networks and value chains, where the Italian MEs operate as pivots. MEs can also operate profitably in industry 4.0, which enhances innovations in digitized factories. However, the effects of transition from medium to large size should be better analyzed, also in terms of larger financial needs. Based on the emerging findings, in fact, this change is likely to reduce their competitiveness.

Policy implications of this paper lead to public measures supporting local professional training and research \& development investments, avoiding intervention on individual firms. In fact, MEs' role can be better enhanced by improving the social capital of territories where they operate and maintaining efficient institutional setting, characterized by less bureaucracy and more widespread knowledge-intensive services.

\section{Acknowledgments}

We thank the Area Studi Mediobanca for their support, and particularly for the extraction of the necessary data for this study.

\section{References}

Ábrahám, Á., \& White, K. (2006). The Dynamics of Plant-Level Productivity in U.S. Manufacturing. Center for Economic Studies Working Paper, 6-20.

Abramovitz, M. (1956). Resource and Output Trends in the United States Since 1870. American Economic Review, Paper and Proceedings, May, 5-23. 
Abramovitz, M. (1991). Thinking about Growth. And Other Essays on Economic Growth and Welfare. Cambridge: Cambridge University Press.

Accetturo, A., Di Giacinto, V., Micucci, G., \& Pagnini M. (2013). Le cause della più elevata produttività delle imprese nelle aree urbane: Agglomerazione o selezione? [The causes of higher productivity of Urban Areas' firms: agglomeration or selection economies?]. In M. Omiccioli (Ed.), I sistemi produttivi locali (pp. 105-133). Rome: Carocci editore.

Becattini G., \& Coltorti F. (2006) Areas of Large Enterprise and Industrial Districts in the Development of Post-war Italy: A Preliminary Survey. European Planning Studies, 14(8). https://doi.org/10.1080/09654310600852415

Becattini, G. (2000). Il distretto industriale. Turin: Rosenberg \& Sellier.

Becattini, G. (2007). Il calabrone Italia. Bologna: Il Mulino.

Bloom, N., \& Van Reenen, J. (2007). Measuring and Explaining Management Practices across Firms and $\begin{array}{lllll}\text { Countries. Quarterly Journal of Economics, } & \text { 122(4), }\end{array}$ https://doi.org/10.1162/qjec.2007.122.4.1351

Cainelli, G., Montresor, R., \& Vittucci, M. G. (2013). Spatial agglomeration and firm exit: A spatial dynamic analysis for Italian provinces. Working Paper Padua University-Department of Economics and Management Marco Fanno.

Coltorti, F. (2013). Italian Industry: Decline or Transformation? A Framework. European Planning Studies, 21(12), 2037-2077. https://doi.org/10.1080/09654313.2012.722972

Coltorti, F., \& Garofoli, G. (2011). Medium-sized enterprises in Europe. Review of Economic Conditions in Italy, $1,171-203$.

Combes, P. P., Duranton, G., Gobillon, L, Puga, D., \& Roux S. (2012). The productivity advantages of large cities: distinguishing agglomeration from firm selection. Econometrica, 80(6), 2543-2594. https://doi.org/10.3982/ECTA8442

Denison, E. F. (1985). Trends in American Economic Growth, 1921-1982. The Brookings Institution, Washington D.C.

Di Giacinto, V., Gomellini, M., Micucci, G., \& Pagnini, M. (2012). Mapping local productivity advantages in Italy: industrial districts, cities or both? Temi di Discussione, Bank of Italy, 850.

Dosi, G., Grazzi, M., \& Moschella D. (2013, October). The determinants of international competitiveness: A firm-level perspective. Paper presented at the 54th Economists Annual Meeting, Bologna.

Ginzburg, A. (2012). Sviluppo trainato dalla produttività o dalle connessioni: Due diverse prospettive di analisi e di intervento pubblico nella realtà economica italiana. Economia \& Lavoro, 2, 67-94.

Levinsohn, J., \& Petrin, A. (2003). Estimating production functions using inputs to control for unobservables. Review of Economic Studies, 70, 317-341. https://doi.org/10.1111/1467-937X.00246

Mahadevan, R. (2003). To measure or not to measure total factor productivity growth? Oxford Development Studies, 31(3), 365-378. https://doi.org/10.1080/1360081032000111742

Manasse, P., \& Stanca, L. (2006). Working on the Train? Skill Upgrading and Technical Progress in Italian Manufacturing Firms. Rivista di Politica Economica, 96(3), 279-308.

Marshall, A. (1920, 1961). Principles of Economics. London/New York: Macmillan.

Mauriello, D. (2013, November). Le medie imprese protagoniste di un modello di sviluppo che abbina innovazione e benessere alla coesione sociale. Paper presented at Mediobanca \& Unioncamere Annual Meeting, Rome.

Maza, A., Villaverde, J., \& Hierro, M. (2009). Regional productivity distribution in the European Union: which are the influencing factors? European Planning Studies, 17(1), 149-159. https://doi.org/10.1080/09654310802514052

Mediobanca \& Unioncamere. (2013). Le medie imprese industriali italiane (2002-2011) [Annual Report on Italian manufacturing medium-sized firms]. Milan: Mediobanca and Unioncamere.

Mill, J. S. (1848). Principles of Political Economy with some of their Applications to Social Philosophy. Longmans, Green and Co. 
Solow, R. (1957). Technical Change and the Aggregate Production Function. The Review of Economics and Statistics, 39(3), 312-320. https://doi.org/10.2307/1926047

Solow, R. (1987). Growth Theory and After. Prize Lecture. The Nobel Foundation.

Sraffa, P. (1926). Le leggi della produttività in regime di concorrenza. In Saggi. Bologna: Il Mulino

Syverson, C. (2011). What Determines Productivity? Journal of Economic Literature, 49(2), 326-365. https://doi.org/10.1257/jel.49.2.326

\section{Appendix}

\section{The Mediobanca database}

Area Studi Mediobanca (Mediobanca Research Division) provides a database of company data mainly collected from the financial statements published by Italian firms. The criteria for processing and classifying entries are homogeneous for all the annual surveys published by Mediobanca, which cover the major Italian companies, the major worldwide multinationals, the "Fourth Capitalism" Italian companies, and the foreign MEs. The Fourth Capitalism includes MEs and medium-large sized firms. In view of this study, we used the data of the universe of Italian MEs, annually recorded in the survey conducted in partnership with Centro Studi of Unioncamere. The universe is identified based on the following criteria: i) limited companies; ii) autonomous ownership; iii) between 50 and 499 employees, counted at the Group level, when applicable; iv) between 15 and 330 million euros of sales. Data are collected from the annual financial statements filed in the Italian Companies Register. The ownership structure is checked through the Shareholders' Register and internal sources.

Financial statements are carefully reclassified in three different sections: balance sheet, income statement, details on cash flow and assets/liabilities changes. As a non-exhaustive example, the income statement shows net sales, value added, cost of labor, operating margins, and current profit or loss; the balance sheet classifies entries based on the financial criterion, distinguishing current items from fixed ones; the asset changes include annual capital expenditures, disposals of assets, and year-end adjustments. Telephone surveys are never used, since the official documents contain all the necessary data for reclassification.

Firms are classified according to the Ateco 2007 economic codes. They are further classified, based on their operational headquarters, by city, province, area according to Becattini and Coltorti (2006) approach (districts, large firm provinces and residual ones); for this study we also identified the urban areas as provinces with more than 2 million inhabitants, the highly populated areas as provinces with more than 500 thousand inhabitants, district areas and local manufacturing systems. Districts are identified based on a criterion of prevalence of information sources (see Mediobanca-Unioncamere, 2013, pp. XXV-XXXIII). The coding also considers the technological intensity, according to the Oecd methodology, and the prevalence of "Italian style (made in Italy) goods".

\section{Notes}

Note 1. See Coltorti, 2013, Mediobanca and Unioncamere 2013, and the numerous other studies mentioned in the bibliographic references of the Fourth Capitalism section in the Area Studi Mediobanca website (www.mbres.it).

Note 2. A previous version of this study was presented at the "Incontri di Artimino sullo sviluppo locale 2013/2014".

Note 3. The last census made by Istat identified just 176 active firms in all industries with at least 1,000 employees, which count for $11 \%$ of the total employment in Italy. In 2011, the manufacturing firms with at least 1,000 workers were 95 and represented 5\% of the Italian manufacturing workers.

Note 4. «The increase of production [...] is a result of the increase either of the elements themselves [Labor, Capital and Land], or of their productiveness» (Mill, 1848, I.10.4).

Note 5. The factors considered by Denison include education, age, sex, re-allocation of resources (from agriculture to non-agricultural sectors), pollution, health and safety at work, union conflicts, and weather trends in agriculture.

Note 6. These data come from the Unioncamere survey of October 2013; see Mauriello (2013).

Note 7. See in section 3.2 how we measure the industry-relative variables. 
Note 8. See Ginzburg (2012) for an exhaustive discussion.

Note 9. In this way, we removed the problem of errors in the calculation of the Istat deflators (Coltorti, 2013), maintaining the impact of improvements in the quality of products (def suffix in variable names). We used the capital goods deflator for the invested capital (defl suffix).

Note 10. To allow a more accurate estimate of the production function, considering the economic trends of the regional context.

Note 11. We obtain this formulation of the Cobb-Douglas from relationship (1), imposing the constraint of constant RTS, and assuming that all the inputs can be referred to L and K (Solow, 1957).

Note 12. IBM, SPSS Statistics, version 20.

Note 13. Based on both the Kruskal-Wallis non-parametric test and mean test of paired samples (data not included for brevity).

\section{Copyrights}

Copyright for this article is retained by the author(s), with first publication rights granted to the journal.

This is an open-access article distributed under the terms and conditions of the Creative Commons Attribution license (http://creativecommons.org/licenses/by/4.0/). 